\title{
Study on the Mechanical Properties of Metal Rubber Inner Core of O-Type Seal with Large Ring-to-Diameter Ratio
}

\author{
Yangyang Yang, ${ }^{1,2}$ Zhi Ying Ren $\mathbb{D}^{1,2}$ Hongbai Bai $\mathbb{C}^{1,},{ }^{1,2}$ Ding Shen, ${ }^{1}$ and Bin Zhang ${ }^{1,2}$ \\ ${ }^{1}$ School of Mechanical Engineering and Automation, Fuzhou University, Fuzhou 350116, China \\ ${ }^{2}$ Engineering Research Center for Metal Rubber, Fuzhou University, Fuzhou 350116, China \\ Correspondence should be addressed to Zhi Ying Ren; renzyrose@126.com
}

Received 19 June 2019; Revised 10 December 2019; Accepted 21 December 2019; Published 29 February 2020

Academic Editor: Aniello Riccio

Copyright (C) 2020 Yangyang Yang et al. This is an open access article distributed under the Creative Commons Attribution License, which permits unrestricted use, distribution, and reproduction in any medium, provided the original work is properly cited.

\begin{abstract}
In view of the problems of ordinary rubber seals, such as high- and low-temperature resistance, easy aging, and insufficient loadbearing performance, $\mathrm{O}$-type metal rubber seals with large ring-to-diameter ratio were prepared by the cold stamping method using stainless steel wire as raw material. The effects of heat treatment and porosity on the compression and tensile properties of test samples were investigated. Under uniaxial compression testing, it was found that the test sample had typical hysteresis characteristics, and the loss factor and energy dissipation of the sample with the same size and different porosity increased with the decrease of porosity. The loss factor and energy dissipation of the heat-treated sample were lower than those of the untreated sample. Thus, the smaller the porosity, the greater the change of loss factor and energy dissipation. Under uniaxial tensile testing, obvious stage changes were found during the tensile process, which included a linear elasticity stage, the formation and development stage of wire breakage, the one-by-one fracture stage of wires, and the complete failure stage of the sample. The yield strength, ultimate tensile strength, and modulus of elasticity of four samples with different porosity were measured, and it was found that the three parameters increased with the decrease of porosity. Moreover, the thermal treatment conductivity increased with the decrease of porosity. The aforementioned three parameters were generally increased. This indicated that metal rubber materials have good mechanical properties under high-temperature environments, which effectively solves the problem of vulnerability to aging and failure of ordinary rubbers under normal working conditions and has strong practical engineering significance.
\end{abstract}

\section{Introduction}

O-rings are types of seals commonly used in sealing devices. Their performance and service life are directly related to the reliability, safety, and maintainability of mechanical systems [1-4]. At present, the O-ring material is mainly rubber, such as natural rubber $(\mathrm{NR})$, nitrile-butadiene rubber (NBR), fluorine rubber (FKM), silicone rubber (MPQ), chloroprene rubber (CR), and polyurethane rubber (PU) $[5,6]$. These materials demonstrate excellent performance in static sealing applications at room temperature; however, at low temperatures, it's easy for them to harden and lose their elasticity. In addition, they are prone to aging failure at high temperatures, they don't easily withstand shear stresses under high pressure, and they are prone to occlusion or fracture, which make them ineffective [7]. With the progress of science and technology, more stringent requirements have been put forward for the equipment working environment, such as high and low temperatures, high pressure, high speed, strong corrosion, and nuclear radiation. Due to its inherent chemical properties, ordinary rubber and plastic materials don't easily adapt to extreme working environments. Therefore, it is necessary to seek a new material able to promote the progress of sealing and leak prevention technology under demanding working conditions.

Metal rubber (MR) is a porous damping elastic material, which is made of metal wire by cold stamping. It is a spatial network structure fabricated by interlacing metal wires [8-10]. It has good damping characteristics and elasticity under external loading. Due to its mechanical properties, research teams have begun using metal rubber in the field of sealing. As it can be seen in Figure $1[7,11]$, metal rubber seals are made of $\mathrm{MR}$ as the inner core elastomer, while copper, 

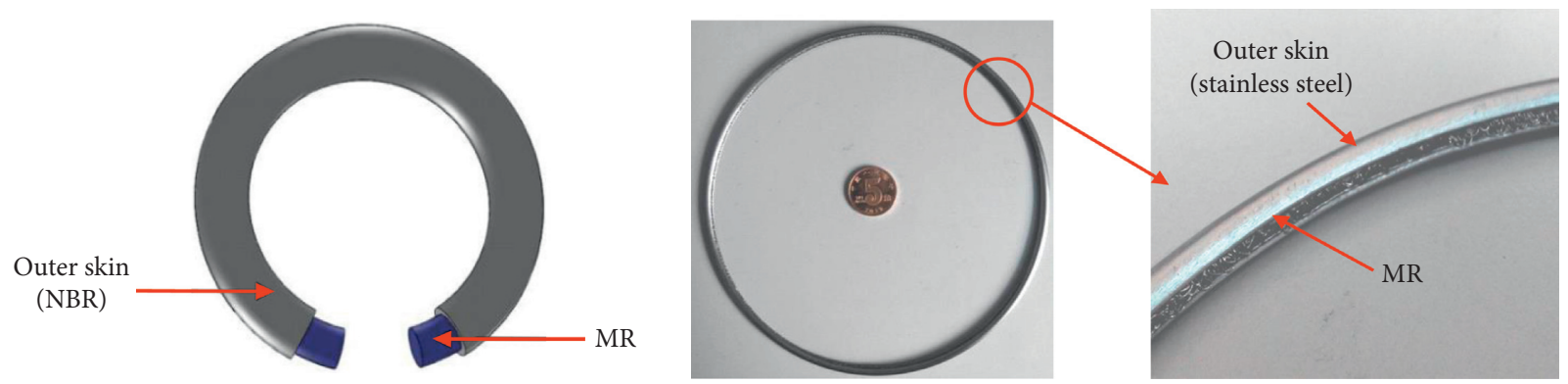

Figure 1: Metal rubber seals [7, 11].

stainless steel, or special high-temperature resistant rubber are used as the outer skin [11]. Since there is no ordinary chemical rubber in their structure and their fatigue aging life is longer, they are especially suitable for sealing requirements under high and low temperature, large temperature difference, radiation, and corrosion environments [12].

At present, the research on metal rubber sealing materials (MRSM) is in the ascendant in China and abroad. In particular, the Samara National University of Aeronautics and Astronautics of Russia is in the forefront of the world and has published some academic achievements [13]. The MR sealing parts developed by the aforementioned University have been applied in practical engineering $[14,15]$. The Jiang Hongyuan team of the Harbin University of Technology (in China) carried out preliminary research and investigation on MR seals. More specifically, they prepared O-type MR seals with different materials [16], studied their sealing mechanism [17], established static sealing simulation models [18], performed sealing performance tests in high-temperature environment [19], built a special test platform for MR seals [20], tested the sealing performance of MR [21], studied the performance degradation of MR seals and established the life prediction model of MR seals [22], analyzed the gas sealing performance of MR seals [23], and so on. Their results have laid the experimental and theoretical foundation in the field of sealing and leak prevention. The MR material itself has good mechanical properties and can work normally under a high-temperature environment, while it effectively solves the aging failure problem of ordinary chemical rubbers in practice [24-27]. With the development of the sealing field, the demand for O-type MR seals with large ring-to-diameter ratio $(110: 4)$ is increasing; however, this is associated with some problems, such as difficulty in preparation and limited research on performance characterization. Therefore, this paper will investigate the influence of the heat treatment process, porosity, and other process parameters on the uniaxial compression and tension mechanical properties of O-type MR seals with large ring-to-diameter ratio. This paper can prove that O-type MR seals can work normally under high-temperature environments and solve the aging failure problem of ordinary chemical rubbers in practice.

\section{Experimental Preparation}

In this paper, based on the automatic winding process of $\mathrm{MR}$ blank, through the numerical control blank winding equipment as shown in Figure 2(a), the blank winding parameters are set to prepare the blank of the MR seal. First, 304 (06Cr19Ni10) austenitic stainless steel was produced by the cold drawing process and was used as the raw material of the wire. The diameter of the wire was $0.15 \mathrm{~mm}$. The wire was wound into a spiral coil using a special winding equipment, and after stretching and unloading, the spiral coil was wound on the NC (numerical control) blank winding equipment and was prepared on a core barrel based on a certain winding path. The prepared blank is shown in Figure 2(b).

After the preparation of the MR blank was completed, the blank was placed into a designed stamping die, and limited tonnage stamping was carried out in a THD32-100 four-column hydraulic press. In this paper, the limited tonnage of MR stamping varied in order to produce different porosity. The specific samples (inner diameter $276 \mathrm{~mm}$, cutoff diameter $2.5 \mathrm{~mm}$ ) are shown in Figure 3. Finally, according to the requirements of this test, four samples with different porosity were selected and heat treated in an atmosphere furnace, in order to test and analyze the effect of heat treatment on the material properties. In this paper, the stress relief tempering method is used to treat the test sample (as shown in Figure (4) to eliminate the residual stress produced in the preparation process of the metal rubber material. The test equipment for heat treatment is the boxtype atmosphere furnace, as shown in Figure 5.

Four sets of samples with different porosity (51.5\%, $57.6 \%, 63.7 \%$, and $69.7 \%$ ) were prepared. Scanning electron microscopy (SEM) was used to observe and analyze the internal microstructure of the samples in detail. The SEM photos of the sample with $69.7 \%$ porosity were chosen as the analysis object (Figure 3). The spiral metal wires in the sample were intertwined and connected to each other, forming a closely connected porous fiber network structure. In addition, the MR material is an energy dissipation material with typical hysteresis characteristics. The maximum elastic potential energy of the MR is the shadow area in Figure 6(a), its energy dissipation is the shadow area in Figure 6(b), and the formula for calculating the loss factor of the metal rubber $[8,28]$ is as follows:

$$
\eta=\frac{\Delta W}{\pi W}
$$

\section{Experimental Process and Analysis}

3.1. Uniaxial Compressive Process of MRSM. For the uniaxial compression test, a WDW-T200 microcomputer controlled 


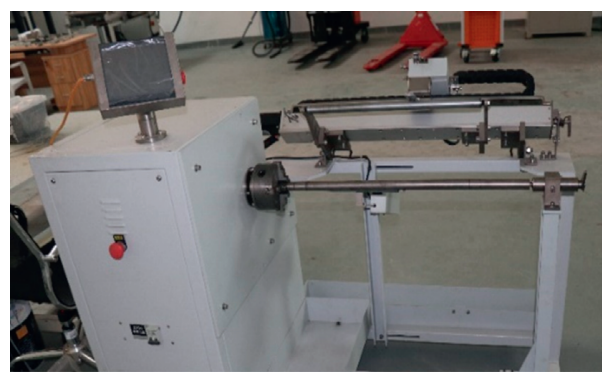

(a)

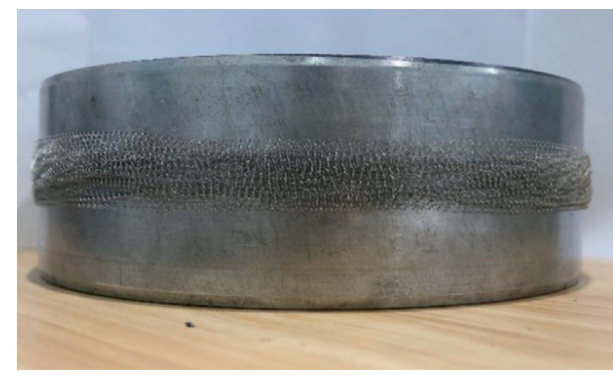

(b)

FIGURE 2: MRSM blank experimental preparation process. (a) NC blank winding equipment. (b) MRSM blank.

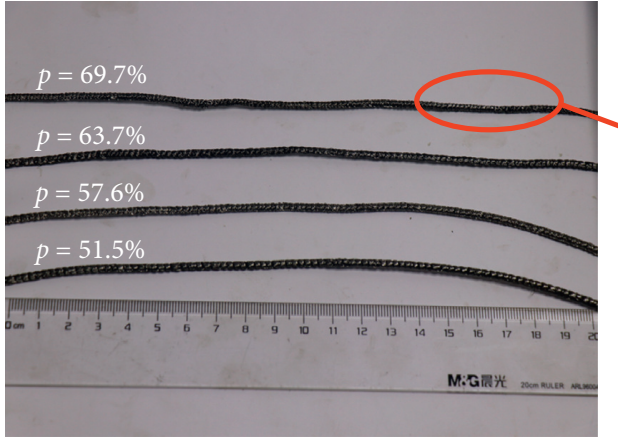

(a)

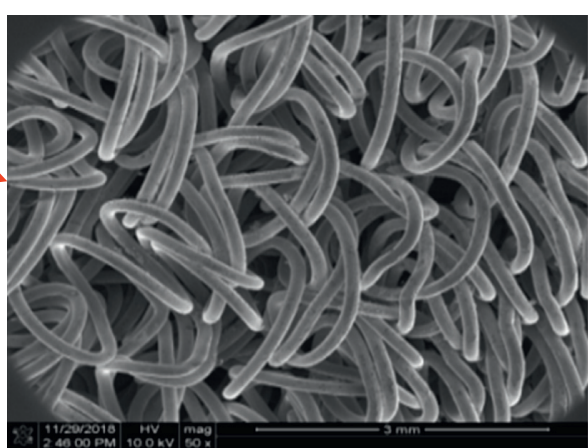

(b)

FIGURE 3: (a) MRSM test samples. (b) SEM of MRSM test sample.

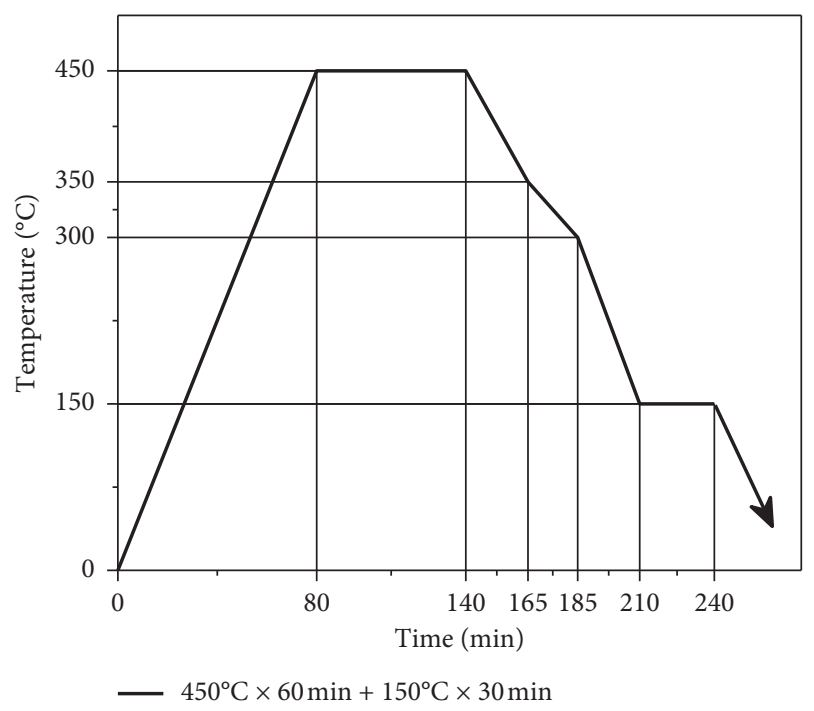

FIGURE 4: Heat treatment process parameters of the MR.

electronic universal testing machine was employed, the maximum test force of the testing machine is $200 \mathrm{kN}$, and the measurement accuracy is better than $\pm 0.5 \%$. The positioning displacement is set as the jump condition to control the return trip in the test. The displacement rate was $0.5 \mathrm{~mm} / \mathrm{min}$, and the load cell range was $1 \mathrm{kN}$. The force and displacement changes during loading and unloading were recorded in real time. The quasi-static loading and unloading fixtures are shown in Figure 7.

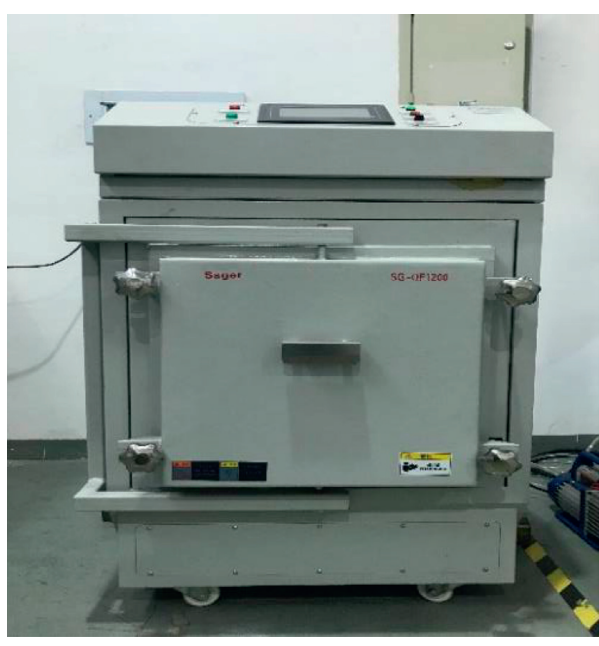

FIgURE 5: Box-type atmosphere furnace.

3.1.1. Effect of Porosity on the Uniaxial Compressive Properties. MR is a typical porous material. The porosity is its essential characteristic and affects its mechanical properties. When analyzing the application of MRs in practical engineering, it is helpful to test the effect of porosity on the material properties. Figure 8 shows the force-displacement diagram of four test samples with different porosity under different loads. It can be seen that the hysteresis phenomenon of the specimen of the same porosity increased with the increase of load. This can be attributed to the fact that, with the increase of compression deformation, the positive 


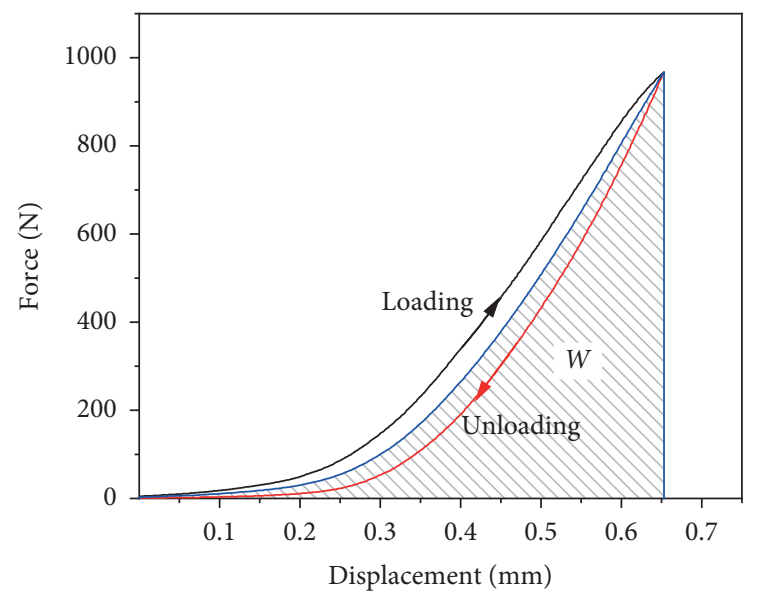

(a)

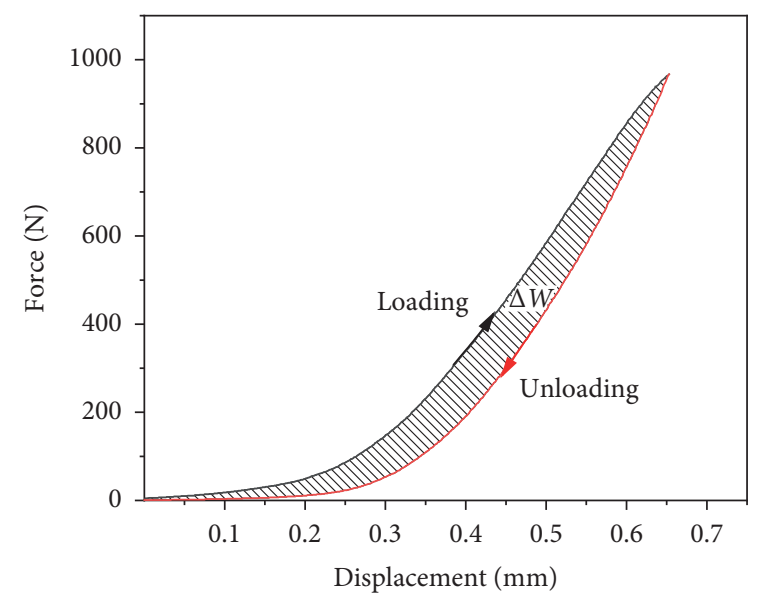

(b)

FIGURE 6: Force-displacement hysteresis curve of the metal rubber.

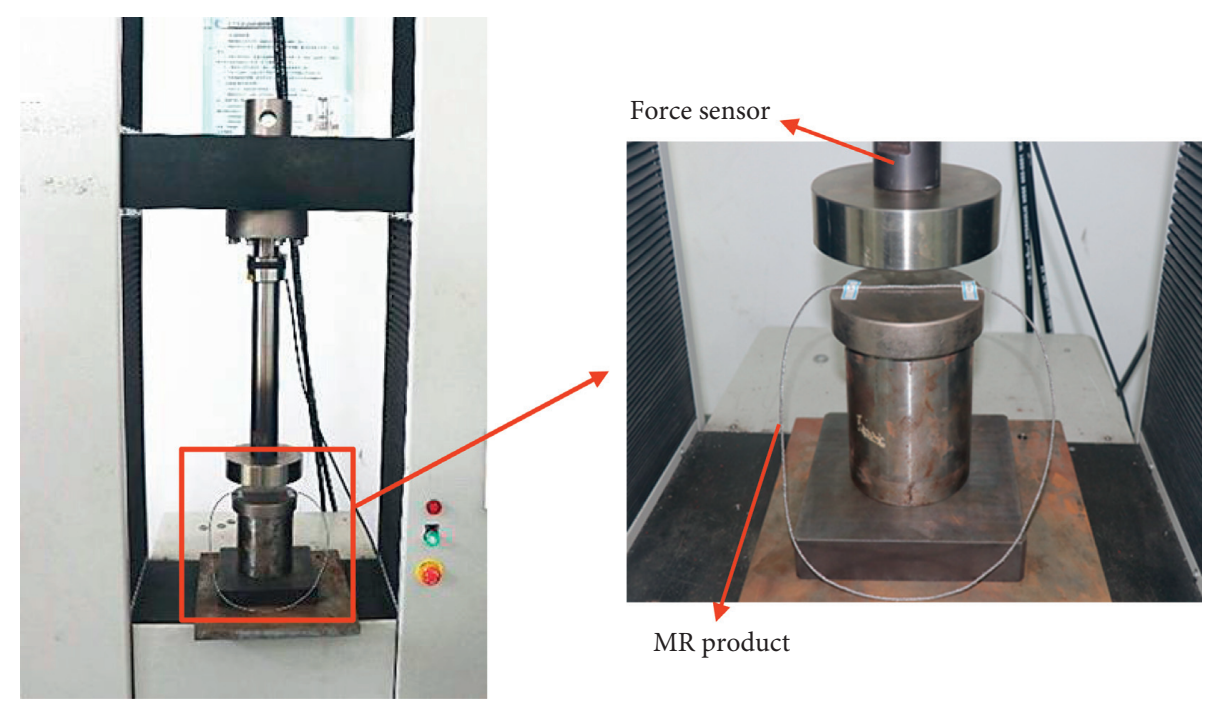

FIgURE 7: MRSM quasi-static loading-unloading process.

pressure and contact area between the stainless steel wires within the specimen increased, and the friction force between the metal wires increased, leading to an increase in the compressive capacity of the specimen, which provided better resilience in sealing. It needs to be ensured that after pressure relief its elasticity can be restored and it can work normally.

Figure 9 demonstrates a comparison diagram of the influence of porosity on compression performance. The force-displacement curves of the four test samples with different porosity under $400 \mathrm{~N}$ and $800 \mathrm{~N}$ loads were selected to be presented in this paper. It was found that within a certain range of porosity under the same load, the greater the porosity of the test sample, the better its resilience and the greater the working load that the test sample can withstand. In addition, under the same load, the larger the porosity of the test sample, the larger the hysteretic area and the greater the energy consumption. In order to quantitatively analyze the effect of porosity on energy dissipation, the loss factor and energy dissipation results of different test samples under the same load were calculated according to formula (1) using MATLAB (Table 1). According to Table 1, it can be quantitatively deduced that both the loss factor and energy dissipation increased with the increase of porosity; that is, within a certain range of porosity, the greater the porosity, the better the energy absorption effect. The energy dissipation increased relatively slowly with the increase of the loss factor. This was because both the energy dissipation and the maximum elastic potential energy increased with the increase of porosity, and the increase in rate of the maximum elastic potential energy was greater than that of the energy dissipation rate. The energy dissipation and loss factor values of all test samples were small, due to the fact that the cross section of the test samples was small and the amount of spiral wire was limited. During compression, the inner wires of the test samples could not form more contact surfaces; that is, the friction force between the wires was lower, which made the test samples insufficient to absorb more energy. 


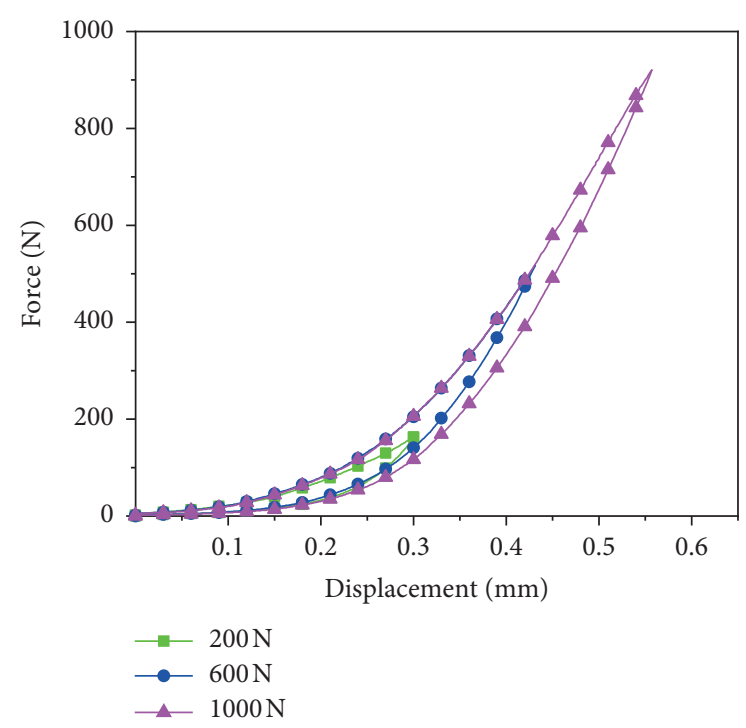

(a)

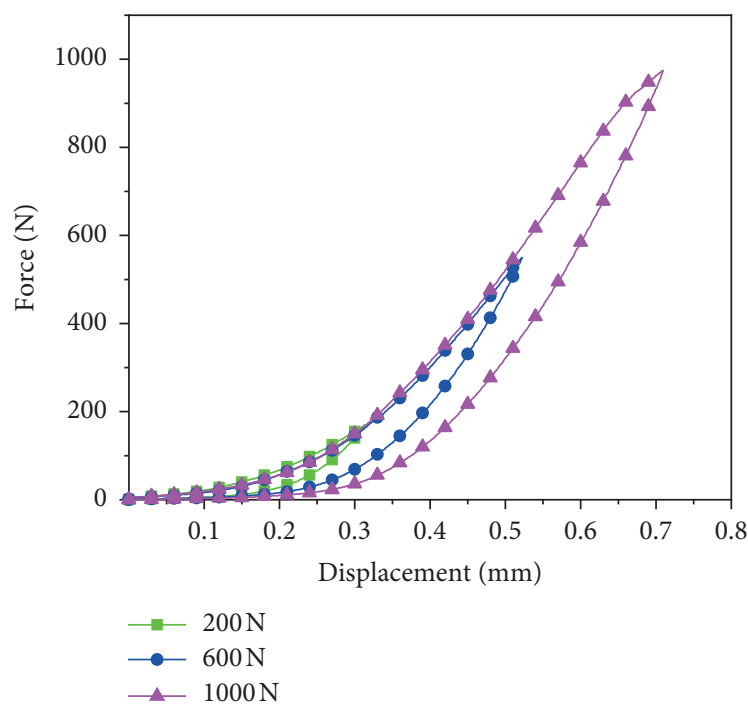

(c)

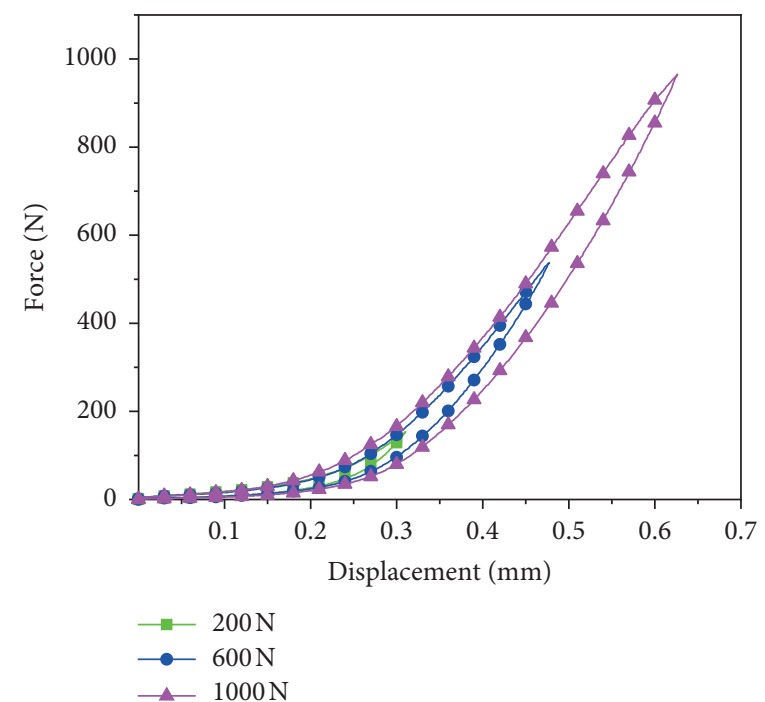

(b)

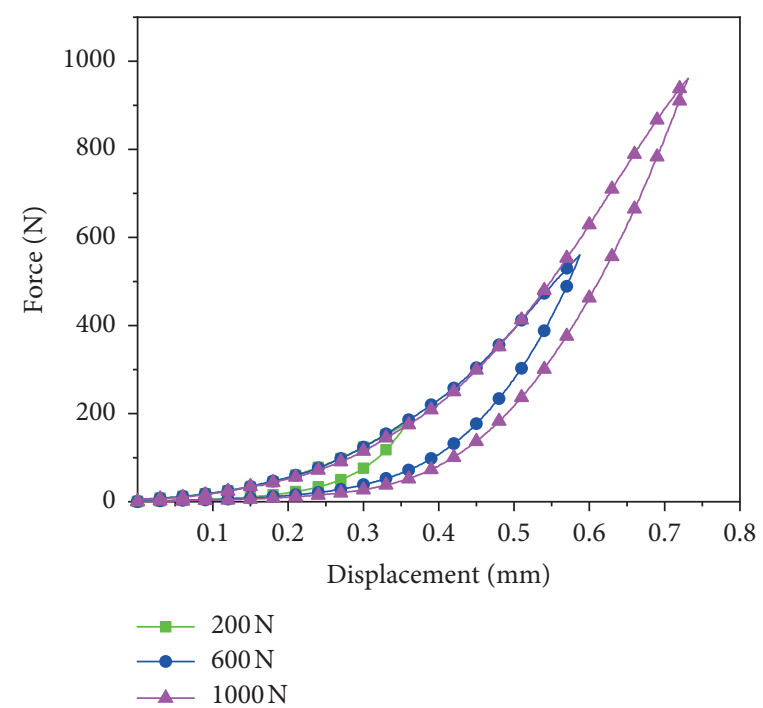

(d)

Figure 8: Displacement variation diagram of sample under different loads. (a) Porosity $=51.5 \%$. (b) Porosity $=57.6 \%$. (c) Porosity $=63.7 \%$. (d) Porosity $=69.7 \%$.

3.1.2. Effect of Heat Treatment on the Uniaxial Compressive Properties. In the present study, the O-type MR sealant with a large ring-to-diameter ratio was prepared by the cold stamping method and it has a spatial network structure with interwoven metal wires and good nonlinear elastic mechanical properties. However, in the process of weaving the blank, uneven laying, wire breakage, and/or cracks may inevitably weaken the mechanical properties of the sample. In order to reduce such deficiencies, the sample usually needs to be postprocessed. The heat treatment process has a greater impact on the mechanical properties of the test samples; thus, the effect of heat treatment on the performance of the sample was investigated under compression testing. Figure 10 shows a force-displacement comparison diagram of four samples with different porosity under the same load after heat treatment together with their respective samples without heat treatment. Table 2 shows the effect of heat treatment on the loss factor and energy dissipation of four samples with different porosity under the same load calculated by formula (1) using a mathematical software.

In Figure 10, it can be seen that both the heat-treated and the untreated samples exhibited similar hysteresis characteristics. Under the same displacement, the heat-treated samples can bear larger loads than the untreated samples; however, the energy consumption of the former was obviously smaller than that of the latter. In Table 2, the influence of heat treatment on the test sample is quantitatively analyzed. For samples with the same porosity, the loss factor and energy dissipation of the heat-treated sample were smaller than those of the untreated sample. The variation of loss factor was between 0.17 and 0.55 , and the variation of energy dissipation was between 0.33 and 0.78 . The variation of both 


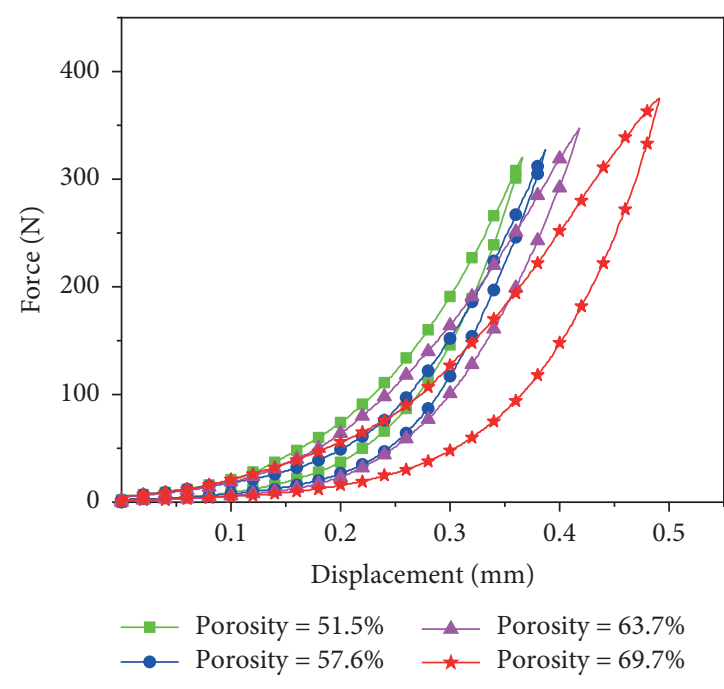

(a)

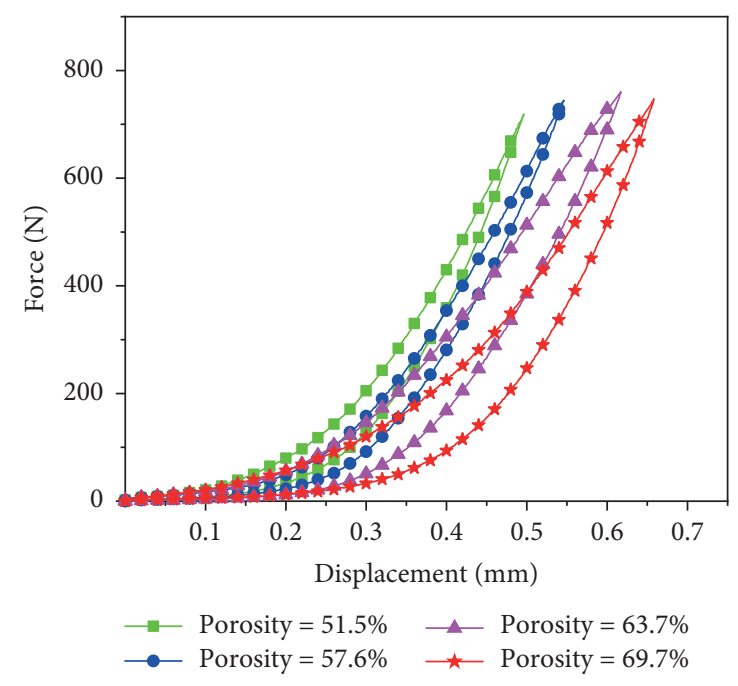

(b)

Figure 9: Comparison diagram of the influence of porosity on compression performance. (a) Static loading $=400 \mathrm{~N}$. (b) Static loading $=800 \mathrm{~N}$.

TABLE 1: Change of loss factor and energy dissipation with porosity.

\begin{tabular}{lcc}
\hline Porosity (\%) & Loss factor $\eta$ & Energy dissipation $\Delta W$ \\
\hline 51.5 & 0.26442 & 0.05371 \\
57.6 & 0.27501 & 0.06469 \\
63.7 & 0.30210 & 0.06688 \\
67.9 & 0.32120 & 0.06893 \\
\hline
\end{tabular}

decreased with the increase of porosity. The energy dissipation of the heat-treated sample was also reduced. The loss factor decreased with the increase of porosity, which indicated that the heat treatment had a great effect on the sample properties. The main reasons for this phenomenon can be attributed to the fact that high-temperature heat treatment reduces the local stress concentration caused by braiding and cold pressing of the metal wires in the sample and reduces the contact points between the metal wires so that the contact area between metal wires in unit volume decreases, resulting in the reduction of deformation resistance and energy dissipation. Therefore, the O-type MR sealant can be prepared by proper heat treatment and by changing the porosity of the sample.

3.2. Uniaxial Tensile Process of MRSM. Considering that the metal rubber seals in this paper are used in the high-temperature environment, the seals will produce large deformation in the nonbearing direction. Based on this, this paper will use the tensile test to study the mechanical properties of the metal rubber material of the metal rubber seal in the tensile state. The uniaxial tensile tests were performed on a CMT4104 electronic universal testing machine. The load cell of the machine was $10 \mathrm{kN}$, the maximum tensile force was $5 \mathrm{kN}$, the accuracy level of CMT4104 electronic universal testing machine is 0.5 , and the measurement range of test force is $0.4 \% \sim 100 \% \mathrm{FS}$ (full scale); the indication error of test force is within $\pm 0.5 \%$ of the indication value, and the test fixture is shown in Figure 11. According to the peak tension measured by multiple pretension tests, the sensor range was $500 \mathrm{~N}$ and the displacement rate was $3 \mathrm{~mm} / \mathrm{min}$. The system had its own data collector. The tensile testing process can be observed in Figure 12.

As it can be seen in Figure 12, the sample has four stages of change during the uniaxial tensile test. That is, in the first stage, as the tension increased, the tightly wound wires were gradually loosened (Figures 12(a) and 12(b)). In the second stage, the spiral wires were gradually straightened with the increase of tension, and there was a little "jitter" (Figures 12(b) and 12(c)). In the third stage, most of the straightened wires were broken one by one due to "cumulative damage" (Figures 12(c) and 12(d)). In the fourth stage, all the intertwined spiral wires were pulled off and material failure occurred (Figures 12(d) and 12(e)). The uniaxial tensile test of O-type metal rubber material differs from that of traditional metal material or rubber material. The tensile fracture of the MRSM is a progressive accumulation of damage, which leads to the one by one breakage of the wires. It belongs to the "flexible fracture" mechanism and eventually leads to complete fracture failure. Tensile fracture of other metals and rubber materials is a process of damage mutation, which belongs to "rigid fracture." There is a great difference in the fracture mechanism between these materials.

\subsubsection{Effect of Porosity on the Uniaxial Tensile Properties.} All the tensile tests in this paper were performed under the same test conditions. Figure 13 shows a force-elongation comparison diagram of four different porosity test samples.

According to Figure 13, the tensile test process demonstrated four different stages (the $69.7 \%$ porosity was used as the sample). The linear elastic stage in the early stage of the tensile test is $0-\mathrm{A}$, which coincides with the stretching from $\mathrm{A}$ to $\mathrm{B}$ in Figure 12. The development stage of the internal 


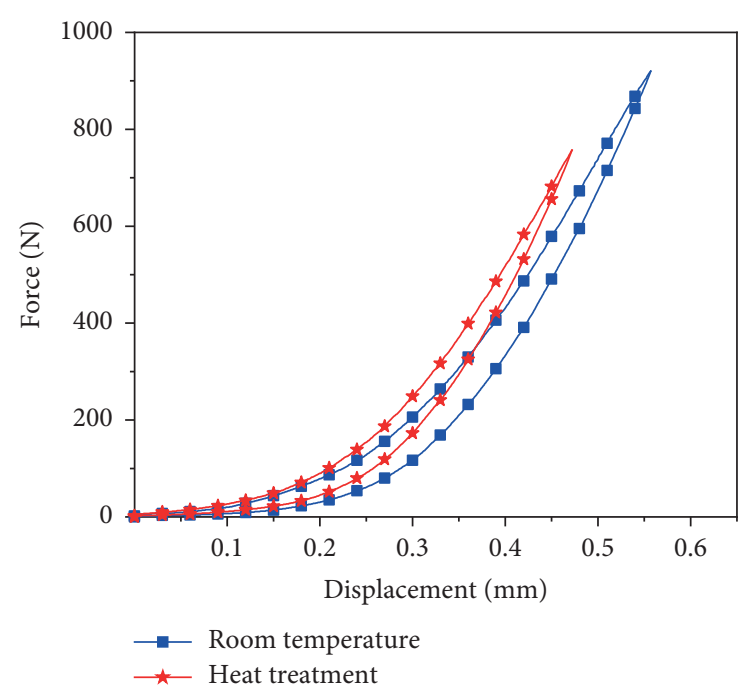

(a)

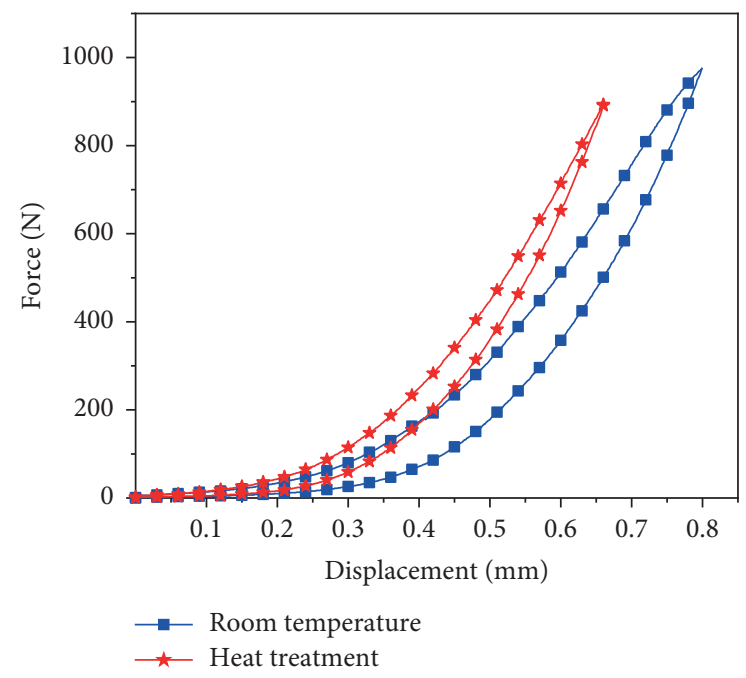

(c)

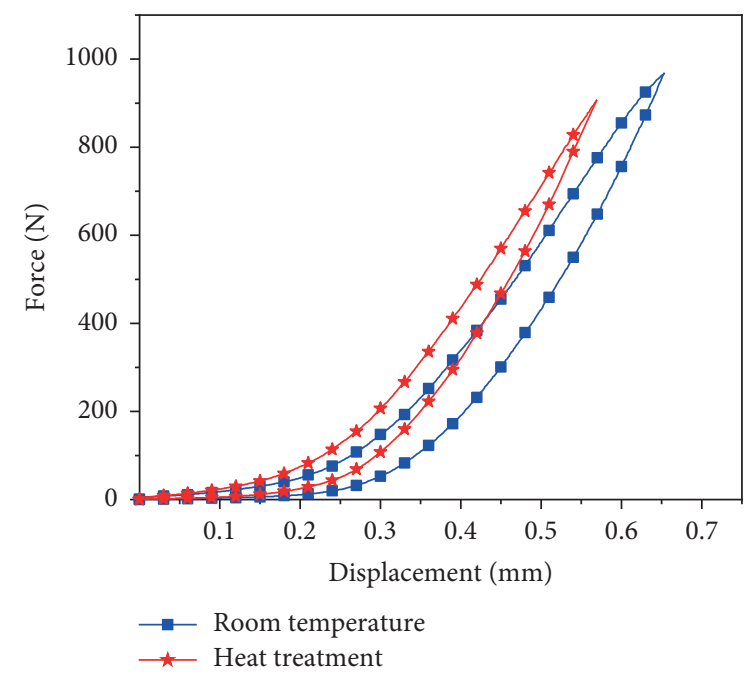

(b)

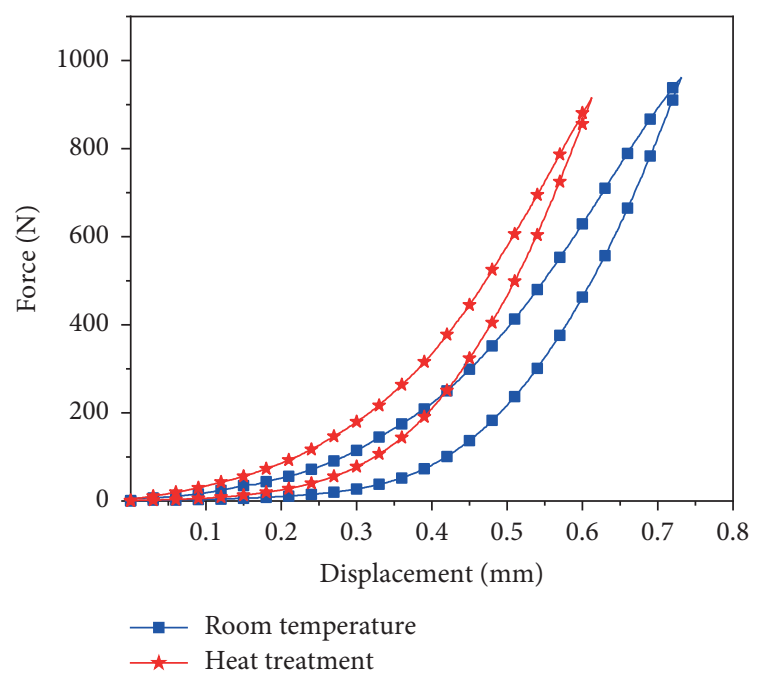

(d)

Figure 10: Comparison of normal temperature and heat treatment of test samples with different porosities. (a) Porosity $=51.5 \%$. (b) Porosity $=57.6 \%$. (c) Porosity $=63.7 \%$. (d) Porosity $=69.7 \%$.

TABLE 2: Change of loss factor and energy dissipation with porosity after heat treatment.

\begin{tabular}{lcc}
\hline $\begin{array}{l}\text { Porosity } \\
(\%)\end{array}$ & $\begin{array}{c}\text { Loss factor (room } \\
\text { temperature, heat } \\
\text { treatment) } \eta\end{array}$ & $\begin{array}{c}\text { Energy dissipation (room } \\
\text { temperature, heat } \\
\text { treatment) } \Delta W\end{array}$ \\
\hline 51.5 & $0.26442,0.21857$ & $0.05371,0.03574$ \\
57.6 & $0.27501,0.19054$ & $0.06469,0.03234$ \\
63.7 & $0.30210,0.18699$ & $0.06688,0.01979$ \\
69.7 & $0.32120,0.14297$ & $0.06893,0.01519$ \\
\hline
\end{tabular}

wire breakage is $\mathrm{A}-\mathrm{B}$, which coincides with the stretching from $B$ to $C$ in Figure 12. The extension stage of the internal wire breakage is $\mathrm{B}-\mathrm{C}$, which coincides with the internal wire breakage in Figure 12. The C-D section is the complete fracture failure stage of the sample after the metal wires were gradually pulled off one by one and is consistent with the $\mathrm{D}-\mathrm{E}$ section in Figure 12. After breaking starting point B, a small range of random fluctuation appeared in the curve, which was due to the fact that the wires inside the sample were first straightened and then broke one by one. The "rebound" phenomenon of microtension occurred during the straightening of the wire. The main reason for this phenomenon is that the potential energy produced by the spiral metal wires interacting with each other was released. In addition, the tensile fracture of metal rubber materials is a process of gradual damage accumulation, which belongs to "flexible fracture," while the tensile fracture of other metal and rubber materials is a sudden damage that belongs to "rigid fracture," which is the main characteristic of metal rubber materials tested under tensile loading and differs from that of other materials.

The tensile yield strength, ultimate tensile strength, and modulus of elasticity of the O-type metal rubber material were obtained according to the existing tensile test formula [29]: 


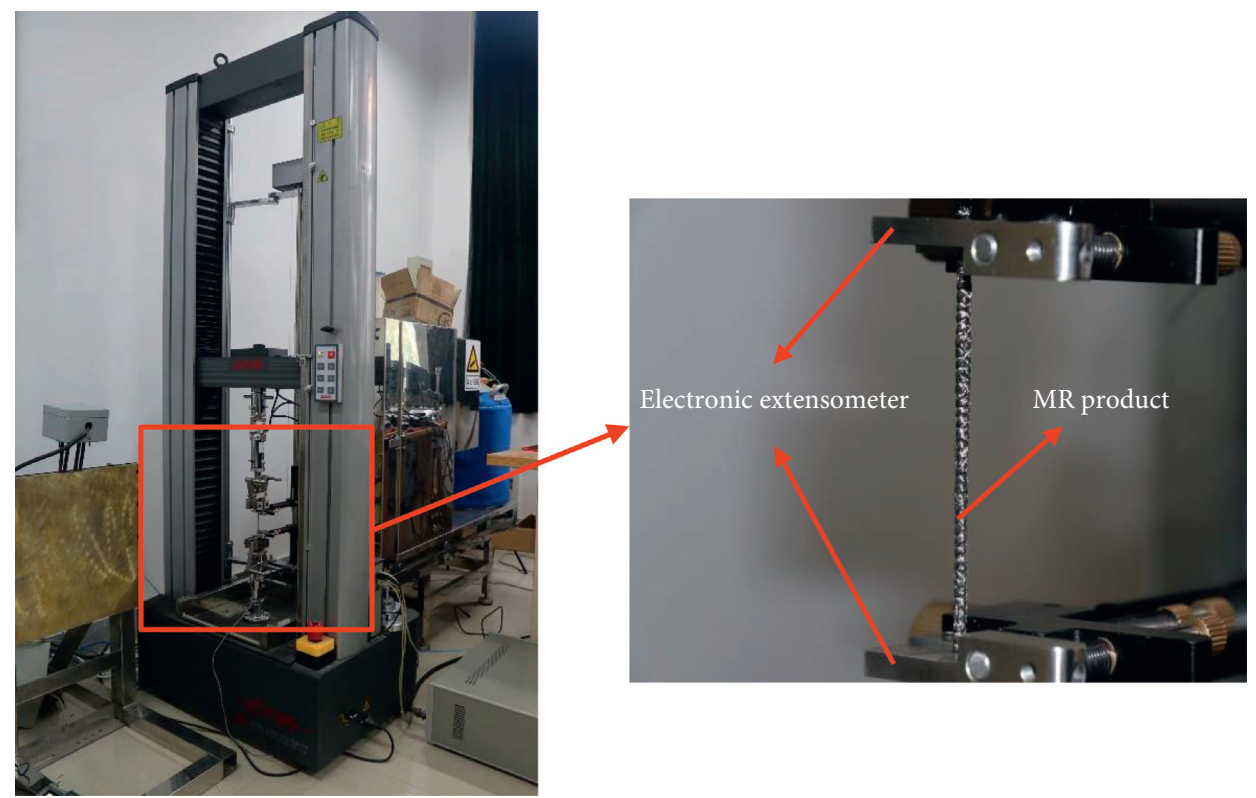

FIgURE 11: Uniaxial tensile testing fixture.

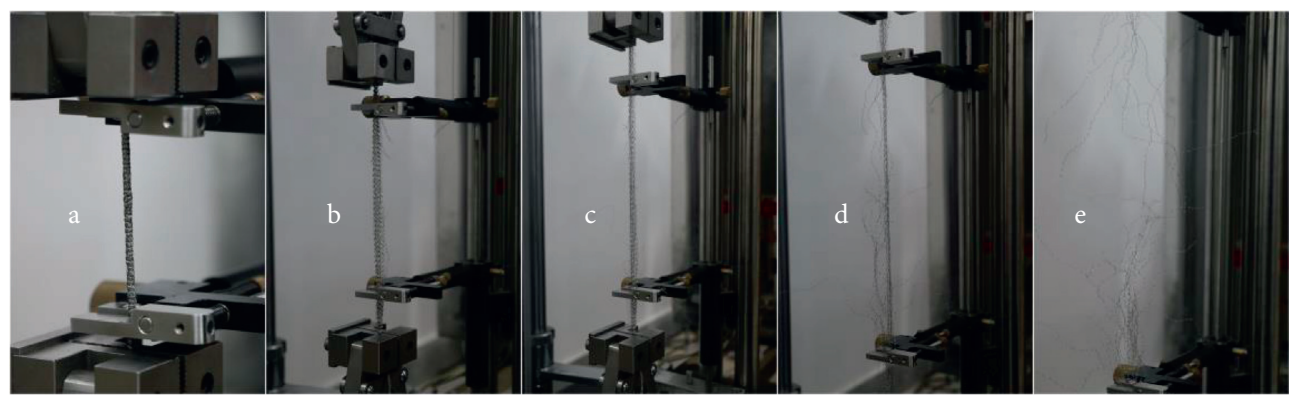

Figure 12: Uniaxial tensile testing process.

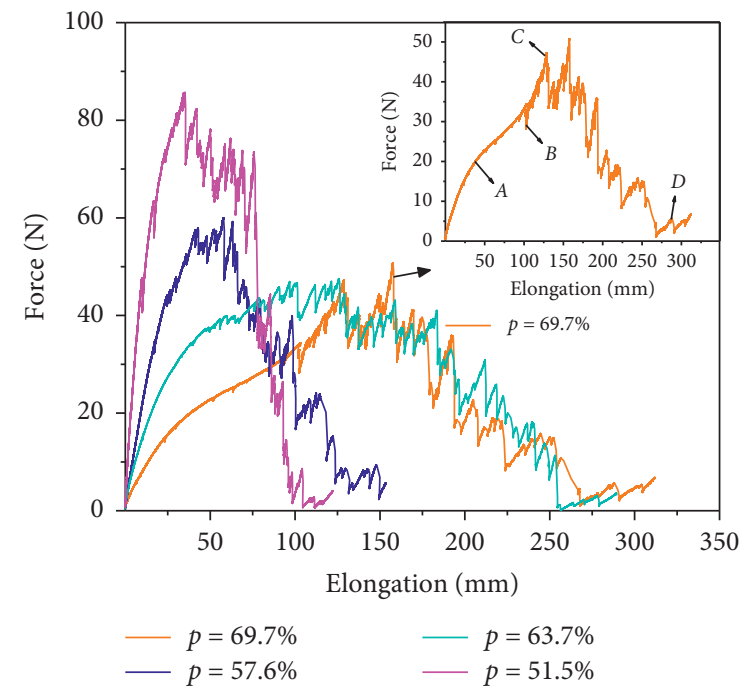

FIgURE 13: Force-elongation curves of specimens with different porosities.

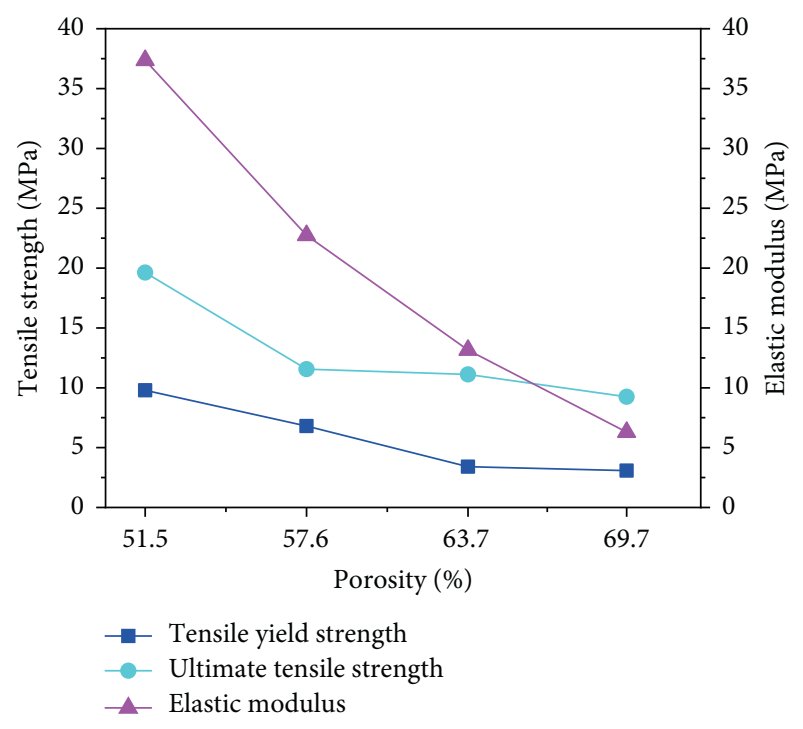

FIGURE 14: Effect of porosity on the tensile strength and the elastic modulus. 


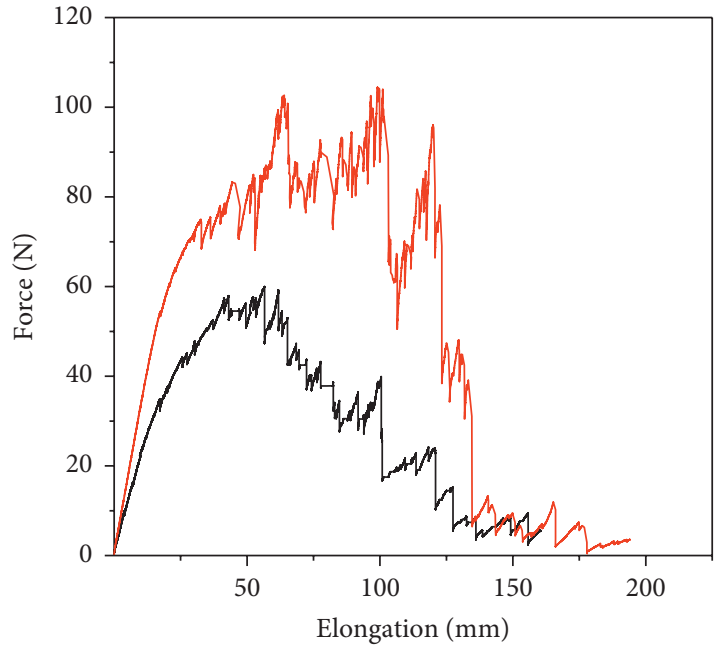

- Room temperature — Heat treatment

(a)

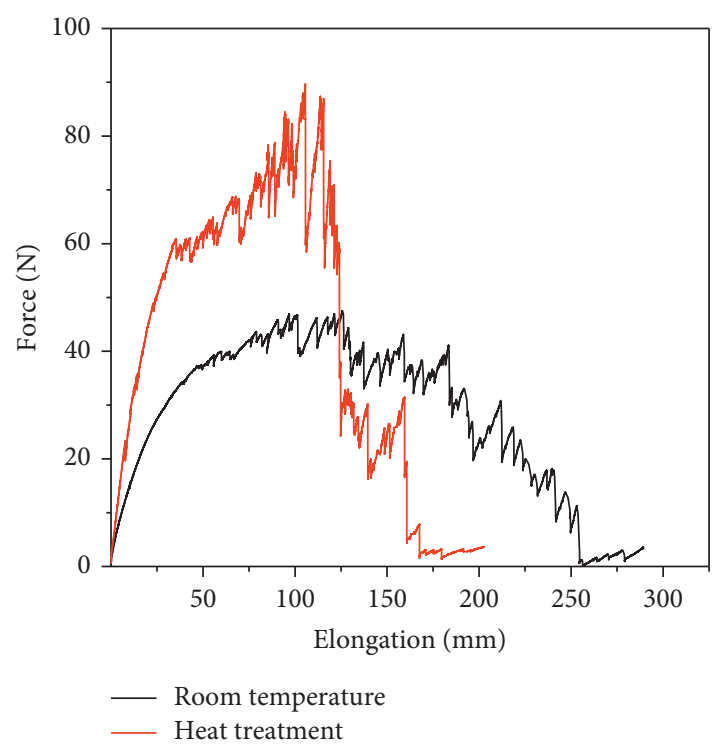

(c)

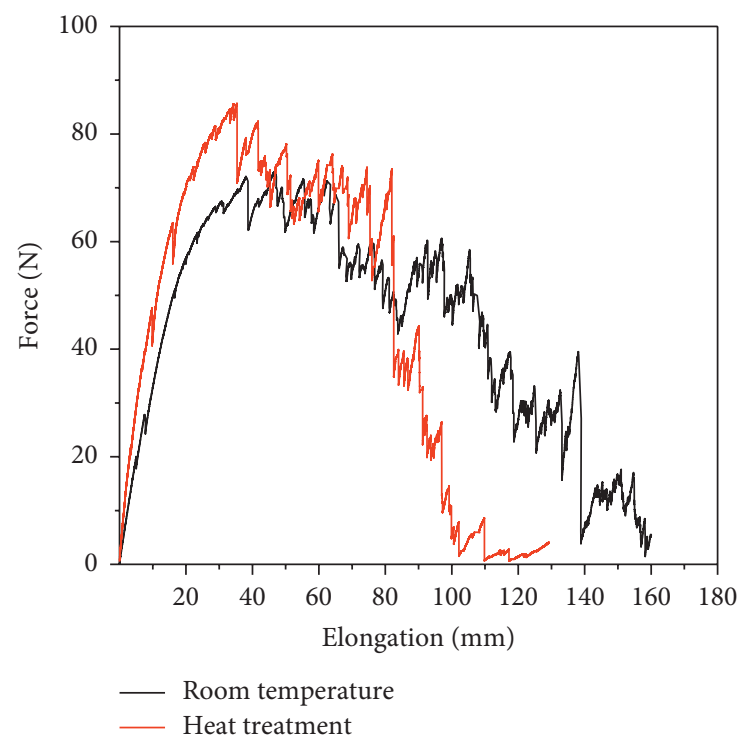

(b)

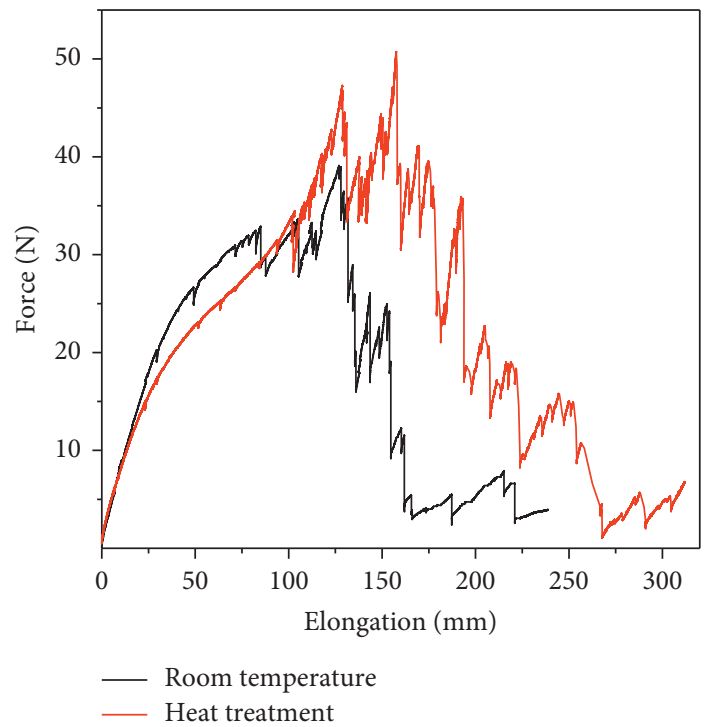

(d)

Figure 15: Effect of heat treatment on material properties. (a) Porosity $=51.5 \%$. (b) Porosity $=57.6 \%$. (c) Porosity $=63.7 \%$. (d) Porosity $=69.7 \%$.

$$
\begin{aligned}
\sigma_{B} & =\frac{F_{B}}{S_{0}}, \\
\sigma_{C} & =\frac{F_{C}}{S_{0}}, \\
E & =\frac{\sigma_{A}}{\varepsilon_{A}}=\frac{F_{A} l_{0}}{S_{0} \times\left(l_{A}-l_{0}\right)},
\end{aligned}
$$

where $\sigma_{B}$ is the yield strength of the test sample, $\sigma_{C}$ is the ultimate tensile strength of the test sample, $E$ is the elastic modulus of the test sample (combined with [29] and tensile test in this paper, point $\mathrm{A}$ is defined as the maximum limit of elastic deformation.), $F_{B}$ is the load of the specimen at point

$B(\mathrm{~N}), S_{0}$ is the original cross-sectional area $\left(\mathrm{mm}^{2}\right), F_{C}$ is the load at point $C(\mathrm{~N}), \sigma_{A}$ is the stress at point $A(\mathrm{MPa}), \varepsilon_{A}$ is the strain at point $A(\%), F_{A}$ is the load at point $A(\mathrm{~N}), l_{0}$ is the original gauge length $(\mathrm{mm})$, and $l_{A}$ is the tensile length of the sample at point $A(\mathrm{~mm})$. The calculated mean values are shown in Figure 14.

According to Figure 14, within a certain range of porosity, it was found that the trend of the three mechanical numerical values of the test sample was basically as follows: elastic modulus $>$ ultimate tensile strength $>$ tensile yield strength. The yield strength, ultimate tensile strength, and elastic modulus of the test sample decreased with the increase of porosity. This was because the higher the porosity of the test sample, the lower the spatial density, the less the 
metal wires in the unit section, and the lower the tensile resistance of the test sample during the tensile test. The change range of the yield strength and the ultimate tensile strength was smaller than that of the elastic modulus. The reasons for this phenomenon are the following. Firstly, the metal rubber is a porous material with large porosity that cannot bear large tensile forces, which results in a relatively low yield strength and ultimate tensile strength. Secondly, the metal rubber used in the tests was a porous material. Its interior was a mesh space structure of spiral metal wires intertwined with each other, which were able to withstand large tensile deformation.

\subsubsection{Effect of Heat Treatment on the Uniaxial Tensile} Properties. In order to eliminate the influence of external factors on the test and ensure the accuracy of the comparison test, the tensile test of this section and the tensile test of the upper section are carried out under the same conditions. The tensile test results of the four samples with different porosity without heat treatment were compared with those of the respective heat-treated specimens (Figure 15).

As it can be seen in Figure 15, under the same porosity, the maximum tensile force of the heat-treated specimen was generally larger than that of the untreated specimen. The initial linear elastic tensile stage of the heat-treated specimen was smoother and the slope was steeper. In addition, the spring-back point, yield point, and plastic deformation point of the heat-treated specimen were generally increased. The reason for this phenomenon is that heat treatment eliminates part of the residual stress in the sample due to the preparation process and the high-temperature heat treatment and releases the mechanical energy (friction potential energy) produced by the cold pressing of the wire. Within a certain range of porosity, with the increase of porosity, the maximum tensile force of the test sample decreased continuously. This was because the test sample with higher porosity contained less metal wires and could not withstand larger tensile load, while the elongation of the test sample increased with the increase of porosity. This was due to the fact that the spiral wires in the sample with larger porosity were loosely connected with each other and the wires during the drawing process were looser. Therefore, it was easier that they be gradually straightened, resulting in an increase in elongation.

From Figure 16, it can be concluded that the yield strength, ultimate tensile strength, and modulus of elasticity of the heat-treated and untreated samples decreased with the increase of porosity, and the heat-treated samples were generally higher than the untreated samples. This can be attributed to the fact that, during preparation, there are individual differences in the internal structure of the test sample, which result in a small deviation in the tensile data. In addition, on the one hand, the internal part of the test sample will be damaged by the heat treatment, which will damage its mechanical properties. On the other hand, in the tension test, the tension fixture will lose slightly when holding the sample due to its structural reasons, and the test accuracy of the equipment itself will have an impact on it.

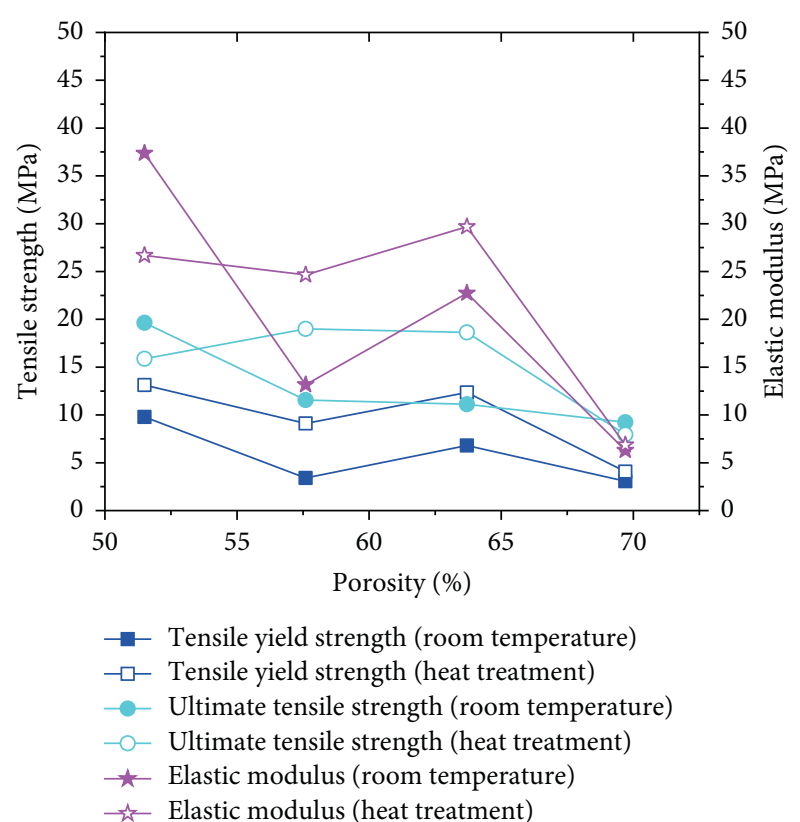

FIGURE 16: Effect of heat treatment on the tensile strength and the elastic modulus.

\section{Conclusion}

In this paper, the uniaxial compression and tensile properties of an O-type metal rubber sealing materials with large ring-to-diameter ratio prepared by the cold stamping method were investigated. The conclusions are as follows.

(1) Under uniaxial compression testing, the test samples demonstrated typical force-displacement hysteresis characteristics, and there was no obvious yield stage in the whole compression process. Within a certain porosity range, for samples of the same size with different porosity, the loss factor and energy dissipation increase with the increase of porosity. Loss factors increased by $0.01059,0.02709$ and 0.01910 successively with the increase of porosity, and energy consumption increased by 0.01098, 0.00219, and 0.00205 successively with the increase of porosity. The sample with the same porosity under the same load, the loss factor, and energy consumption of the heat-treated sample are less than the sample at normal temperature. With the increase of porosity, compared with the samples without overheating treatment, the loss factor of the samples after heat treatment reduced by $0.04585,0.08447,0.115111$, and 0.17823 , successively, and the energy consumption of the samples after heat treatment decreased by $0.01797,0.03235,0.04709$, and 0.05374 , successively. Moreover, the smaller the porosity, the greater the variation of loss factor and energy dissipation.

(2) Under uniaxial tensile testing, the fracture of the specimens was a cumulative damage process, which was different from the sudden fracture of other materials. The tensile fracture belongs to "flexible 
fracture." The tensile yield strength, ultimate tensile strength, and modulus of elasticity of the heattreated and the untreated specimens decreased with the increase of porosity, and the three mechanical values of the heat-treated samples are larger than those of the untreated samples. With the increase of porosity, compared to the test samples without overheating, the yield strength of the heat-treated samples increased by $4.0800,9.1114,12.3561$, and 13.1358, successively, the ultimate tensile strength of the heat-treated samples increased by 7.9519, $15.8766,18.6268$, and 19.00028, successively, and the elastic modulus of the heat-treated samples increased by $6.8570,24.6466,26.6770$, and 29.6768, successively.

In summary, the porosity and the heat treatment process have great influence on the properties of MRSM. The preparation parameters can be adjusted based on the actual working environment, in order to meet the technical requirements. The results of the present study provide important technical guidance for the application of metal rubber materials in the field of sealing and leakage prevention.

\section{Data Availability}

The data used to support the findings of this study are available from the corresponding author.

\section{Conflicts of Interest}

The authors declare no conflicts of interest.

\section{Acknowledgments}

The authors thank the National Natural Science Foundation of China (Grant no. 51805086), the Fujian Provincial Natural Science Foundation (2019J01210), High End Bearing Tribology Technology and Application, National Joint Engineering Laboratory Open Fund Project, Henan University of Science and Technology (201802), and Fujian Province Health Education Joint Research Funding Project (2019-wj01).

\section{References}

[1] S. X. Li, J. N. Cai, Q. X. Zhang, L. Jie, and J. J. Gao, "Performance analysis of O-ring used in compensatory configuration of mechanical seal," Journal of Tribology, vol. 30, no. 3, 2010.

[2] W. Wang and S. G. Zhao, "Influence of structure parameters on the properties of rubber O-ring seal," Lubrication Engineering, vol. 35, no. 1, 2010.

[3] T. T. Lu and W. M. Wang, "Development review of O-ring with rubber material," Hydraulic Seals and Pneumatic Seals, vol. 34, no. 10, 2014.

[4] P. Liu, W. J. Song, Q. L. Jiang, and X. J. Li, "Sealing performance of O-ring in deep sea high pressure environment," Chinese Hydraulics \& Pneumatics, vol. 4, 2017.
[5] X. D. Peng, Y. M. Wang, and X. Huang, "State-of-the-art and future development of sealing technology," Hydraulic Seals and Pneumatic Seals, vol. 4, no. 4, pp. 4-11, 2009.

[6] P. Fu and D. G. Chang, Handbook of Seal Design, Chemical Industry Press, Beijing, China, 2009.

[7] Y. L. Zhao and H. Y. Jiang, Metal Rubber Seal Research on Reciprocating Shaft Sealing Performance, Harbin Institute of Technology, Harbin, China, 2016.

[8] H. B. Bai, C. H. Lu, F. L. Cao, and D. W. Li, "Metal rubber materials and engineering applications," Science Press, Beijing, China, 2014.

[9] K. Wu, H. Bai, X. Xue, T. Li, and M. Li, "Energy dissipation characteristics and dynamic modeling of the coated damping structure for metal rubber of bellows," Metals, vol. 8, no. 7, p. 562, 2018.

[10] Z. Y. Ren, Q. Chen, H. Bai, and Y. Wu, "Study on damping energy dissipation characteristics of cylindrical metal rubber in nonforming direction," Advances in Materials Science and Engineering, vol. 2018, pp. 1-10, 2018.

[11] W. J. Zhang and H. Y. Jiang, Leakage Rate Analysis and Experimental Research on Metal Rubber Seal, Harbin Institute of Technology, Harbin, China, 2014.

[12] H. Yan, Y. H. Xia, and H. Y. Jiang, "Research on the minimum interference of metal rubber sealing component," Lubrication Engineering, vol. 5, no. 5, pp. 14-15, 2005.

[13] X. P. Dong and L. Zhang, New Material-Metal Rubber Modeling and Application, Chemical Industry Press, Beijing, China, 2010.

[14] J. R. An, Handbook of Metal Materials in Common Use at Home and Abroad, Vol. 1, Shanxi Institute of Standardized Information, Xi'an, China, 1984.

[15] H. Yan, Y. H. Xia, H. R. Ao, and H. Y. Jiang, "Research on the manufacturing technology of metal rubber sealing rings with large diameter and small section," Lubrication Engineering, no. 4, pp. 31-32, 2003.

[16] X. M. Huang, W. Shi, and H. M. Wang, "Porous medium leakage flow model of brush seal," Journal of Propulsion and Power, vol. 15, no. 1, 2000.

[17] H. Y. Zhao and H. Y. Jiang, Study on Hermetical Performance and Application of O-type Metal Rubber Component, Harbin Institute of Technology, Harbin, China, 2008.

[18] H. Yan, Y. Zhao, J. Liu, and H. Jiang, "Analyses toward factors influencing sealing clearance of a metal rubber seal and derivation of a calculation formula," Chinese Journal of Aeronautics, vol. 29, no. 1, pp. 292-296, 2016.

[19] L. Wang and H. Y. Jiang, Metal Rubber Sealing System Model Establishment and Simulation Analysis, Harbin Institute of Technology, Harbin, China, 2010.

[20] J. G. Liu and H. Y. Jiang, Seal Characteristics Analysis and Experimental Research on Metal Rubber Seal under High Temperature, Harbin Institute of Technology, Harbin, China, 2015.

[21] Y. C. Li and H. Y. Jiang, Temperature Characteristics of Metal Rubber Seal Research and Dedicated Test Stand, Harbin Institute of Technology, Harbin, China, 2013.

[22] W. Yao and H. Y. Jiang, Failure Model and Performance Degradation of Metal Rubber Seal, Harbin Institute of Technology, Harbin, China, 2017.

[23] T. Yuan and H. Y. Jiang, Analysis and Experimental Study on Gas Sealing Performance of Metal Rubber, Harbin Institute of Technology, Harbin, China, 2018.

[24] J. F. Hou, H. B. Bai, D. W. Li, Y. Y. Wang, and S. Tao, "Experimental research on damping performance of metalrubber shock absorber in high and low temperature 
environment," Journal of Aeronautical Materials, vol. 26, pp. 50-54, 2006.

[25] B. Y. Yan, Dynamic and Static Experimental Study on Metal Rubber Vibration Isolator in High-Temperature Environment, Harbin Institute of Technology, Harbin, China, 2011.

[26] T. Li and H. B. Bai, "Compressive property of knitted-dapped metal rubber at different temperatures," Materials for $\mathrm{Me}$ chanical Engineering, vol. 42, no. 10, 2018.

[27] K. Xiao, H. B. Bai, X. Xue, and Y. W. Wu, "Energy dissipation characteristics and parameter identification of metal rubber coated pipe in high temperature environment," Ordnance Material Science and Engineering, vol. 42, no. 1, 2019.

[28] D. Zhang, F. Scarpa, Y. Ma, K. Boba, J. Hong, and H. Lu, "Compression mechanics of nickel-based superalloy metal rubber," Materials Science and Engineering: A, vol. 580, no. 580 , pp. $305-312,2013$

[29] X. Chen, Z. H. Wang, X. L. Shi, S. P. Feng, and Z. Peng, Engineering Materials, Wuhan University of Technology Press, Wuhan, China, 2010. 